\title{
The history of refugee and newcomer health care in Canada
}

\author{
Austyn Roseborough, Roger Hudson
}

\begin{abstract}
Canada represents a global leader in refugee resettlement, having embraced an identity of multiculturalism that promotes the acceptance of newcomers. A crucial factor in facilitating post-arrival integration of newcomers into Canadian society is the maintenance of good health through the provision of adequate health care services. Throughout the past century, there has been an increase in the number of refugees in Canada, beginning largely in the post-World War period and extending into the second half of the twentieth century. This influx has required the development of health care systems and coverage specific to unique post-arrival medical needs of refugees. The history of refugee health care has been shaped by both policy and advocacy on behalf of refugees, resulting in a larger breadth of coverage today than ever before. This article summarizes the evolution of health care services provided to refugees, challenges that particular populations of refugees have faced in accessing care, and suggestions for continued improvements in refugee access to health care services.
\end{abstract}

\section{INTRODUCTION}

Within the current context of increasing refugee resettlement worldwide, Canada's history of refugee resettlement can serve to inform advancements in refugee care across the world. In 2016 alone, Canada admitted more than 46700 refugees, the highest in over four decades, and the need for resettlement has not diminished in recent years. ${ }^{1}$ Refugees represent individuals who are fleeing persecution in their home country and seek protective services upon arrival in Canada. ${ }^{2}$ Throughout the history of refugees in Canada, governmental policies and public opinion have shaped the evolution of health care services offered to refugees. As a world leader in refugee resettlement, Canadian integration policies and the ensuing social and health-related provisions offered to refugees have reflected a strong framework that facilitates postarrival integration into Canadian culture. This article will briefly explore the historical perspectives of health care for refugees entering Canada, ongoing vulnerabilities for specific refugee subpopulations, and potential strategies for policy reformation to eliminate persisting gaps that hinder integration.

\section{HISTORY OF REFUGEE HEALTH CARE IN CANADA}

Beginning soon after national independence, Canada has consistently had high rates of immigration, resulting in an increasingly multicultural society. Late 19 th and early 20 th century refugees consisted primarily of Anglo-Celtic Protestant or FrancoCatholic families from Western European countries who established agricultural industries and laid the foundations for future Canadian infrastructure. ${ }^{3}$ At the time, refugees seeking asylum were less common in Canada, especially for those representing cultures or religions that faced discrimination. ${ }^{2}$ One of the largest shifts in Canadian refugee history occurred following World War II. In response to the overwhelming numbers of displaced individuals, efforts by organizations such as the United Nations Relief and Rehabilitation Administration (UNRRA) encouraged the acceptance of large numbers of refugees into Canada. ${ }^{2}$ This trend continued throughout the Cold War and the remainder of the 20th century, when Canada would accept thousands of refugees a year, with a peak of over 60000 refugees between 1979 and $1980 .^{2}$

Due to post-war humanitarianism efforts, public opinion towards refugees was favorable. In recognition of the welcoming nature of Canadians towards refugees, the people of Canada received the Nansen Refugee Award from the United Nations High Commissioner for Refugees in 1986. However, bias within refugee policy meant that individuals with disabilities, mental illnesses, or infectious diseases were selected against. ${ }^{4}$ Health status became a selection category for the evaluation of refugees and hindered many from accessing the health care that they required. ${ }^{4}$ The health admission standards discriminated against disabilities and illnesses for which refugees were at higher risk, since they were often fleeing war afflicted countries. ${ }^{2}$ These policies prevented many individuals in need of health care services from being accepted into Canada, and instead, many remained in post-war facilities. ${ }^{2}$

For those refugees accepted into Canada, the government recognized the need to address their health care needs to successfully establish themselves in Canada. In 1957, Canada introduced legislation that would become the Interim Federal Health Plan (IFHP), which covered initial post-arrival medical care for refugees while they navigated the application frameworks required to receive provincial coverage. ${ }^{5}$ The IFHP is still active today, and continues to provide financial assistance for critical health and social services such as medical and dental care, prescription coverage, and vision care. ${ }^{6}$ The foundation of the IFHP was to provide medical care to refugees that was comparable to the care a Canadian would receive, recognizing that the maintenance of health was crucial for their successful integration into Canada. ${ }^{7}$ The IFHP development coincided with the introduction of the federal Hospital Insurance and Diagnostic Services Act, which provided coverage for provincial health plans affecting all Canadians and 
formed the foundation for the Canada Health Act. ${ }^{8}$

Public opinion towards refugees was generally positive through the remainder of the 20th century, with many Canadians embracing the idea of Canada as a safe haven for those in need. ${ }^{4}$ However, in 2012 many refugees faced reductions in health care coverage due to changes made to the IFHP, intended to reduce costs and potential misuse. ${ }^{4}$ The new IFHP divided refugees into tiers, maintaining coverage for government-sponsored refugees while cancelling care for privately-sponsored individuals or refugee claimants. These individuals only received Public Health benefits, which address diseases that are of a public safety concern. ${ }^{9}$ Government-assisted refugees make up a relatively small proportion of the total Canadian refugee population, for example only $21 \%$ in $2005,{ }^{10}$ therefore a large proportion of refugees were affected by the IFHP revisions. Furthermore, these changes to the IFHP disproportionately impacted women and children in particular, due to their historically greater health care needs upon arrival. ${ }^{7}$

The policy changes evoked confusion amongst the health care community, related to the breadth of insurance coverage and increased strain on provincial health care systems required to compensate for the lack of federal coverage. ${ }^{7}$ In light of the 2012 IFHP changes, Canadian physicians began to advocate heavily for refugee care. ${ }^{11}$ The formation of organizations such as the Canadian Doctors for Refugee Care, the Canadian Association of Refugee Lawyers, and Justice for Children and Youth resulted in a Supreme Court challenge of the new IFHP. In 2014, the Supreme Court ruled that the revised IFHP violated Section 12 and Section 15 of the Charter of Rights and Freedoms stating that the policy "serves to perpetuate the disadvantage suffered by members of an additionally vulnerable, poor, and disadvantaged group." ${ }^{4}$ Upon the court's instructions, the IFHP was revised to a charter-compliant version in 2014 and was returned to its pre-2012 status in 2016 with additional pre-arrival care services being offered in 2017. ${ }^{12}$ As a result, the program is more comprehensive today than ever before, promoting a smooth transition for refugees and strengthening Canada's leadership role in refugee care on a global scale.

\section{INCREASED VULNERABILITY IN REFUGEE SUBPOPULATIONS}

While refugees have historically seen improvements over time in the Canadian health care system, there has been stigmatization and oppression whereby subpopulations have experienced discrimination within the health care system. In particular, there was historical discrimination towards female refugees via unequal enforcement of immigration standards between genders. ${ }^{3}$ For example, following World War II, unmarried women were often selected against for admission into Canada due to the preference for family units. There has been improvement in the acceptance of single women as refugees, with Canada instituting the Women Refugee Claimants fearing Gender-related Persecution Guidelines in 1993. This act was enacted to improve the assessment of female refugees by the Canadian Immigration and Refugee Board and acknowledge gender-specific persecution that females may have been subjected to in their home country. ${ }^{13}$ However, while this act may have improved the processing of female refugee claims, women continue to face increased challenges following their arrival in Canada. A study of refugees arriving in 1999 described the greater health care needs of female refugees, especially relating to birth control and prenatal care. ${ }^{14}$ Lack of preventative care such as mammograms or cervical screening in their country of origin, coupled with barriers to accessing health care following their arrival in Canada, suggests that services are not rigorous or personalized for the health care needs of women. ${ }^{6,15}$ In the future, increased emphasis on the unique needs of female refugees and ensuring adequate pre-arrival care will be important for ensuring provision of preventative medicine and for minimizing post-arrival health-related expenses.

Undocumented migrants represent a uniquely vulnerable group due to their precarious status. This includes refugees whose claims have been denied, which represents a significant proportion of claimants; reports indicate that $60 \%$ of refugee claimants between $1997-2007$ and $65 \%$ in 2012 were rejected. ${ }^{15,16}$ Considering the unprecedented worldwide growth in undocumented migration in recent years, further resources should be allocated toward expediting processing of refugee claimants. ${ }^{13}$ Moreover, legal, temporal, and financial challenges impede access to health care services for these individuals. The effects are also evident in large, multicultural environments with greater rates of undocumented migrants, such as in Toronto where reports in 2011 found that up to $13 \%$ of children lacked health care coverage. ${ }^{15}$ In fact, in line with historical evidence, pregnant women and children continue to be disproportionately affected by a lack of documentation, since they often receive inadequate pre-arrival health screenings and experience unanticipated health care needs at a greater rate. ${ }^{17}$ These insufficiencies have stimulated start-up, volunteer-run organizations seeking to address the needs of these subpopulations and advocate for the universality of migrant rights. ${ }^{18}$ The economic and health-related implications of these health care disparities are currently unknown, but given the rise in undocumented immigrant resettlement worldwide, extended bureaucratic timelines for social service applications, and economic repercussions of restricting preventative medicine, there is an overwhelming lack of adaptive strategies currently being implemented to offset potential longterm consequences. ${ }^{1}$

\section{REMAINING CHALLENGES AND FUTURE DIRECTIONS}

Health care for refugees in Canada has evolved throughout the previous century under the influence of public opinion and federal health care policies. Ensuring adequate care following arrival has been a challenging process that is complicated by the unique needs of refugees. ${ }^{19}$ Due to environmental and emotional challenges, refugees experience greater health care needs upon arrival relative to Canadian-born citizens. ${ }^{20}$ These needs have been exacerbated by several barriers, including communication difficulties, limited access to family physicians, and issues navigating the health care system. ${ }^{21}$ A large step towards improvement was taken with the introduction of the IFHP, however, struggles with accessing adequate health care remain a serious issue for many refugees.

Historically, some physicians have been reluctant to take on refugees due to uncertainty surrounding their coverage and the additional work required for clinical reimbursement through 
the IFHP. ${ }^{14,21,22}$ Issues regarding the lack of efficiency in IFHP reimbursement and administration have been noted for many years, with future improvements in this area being crucial for ensuring the IFHP is able to carry out the purpose for which it was created..$^{23}$ Improved education surrounding the care of refugees, reduced clerical barriers, and a simplified process would allow for easier and more effective integration of refugee patients into clinics. ${ }^{22}$ Physician advocacy for refugee care has exemplified the social roles for clinicians in protecting vulnerable populations, and will continue to be important for improving access to treatment. Future studies and improvements in addressing subpopulations of refugees that remain vulnerable such as women, those with disabilities, and those without refugee status will be important for promoting successful and healthy integration of refugees into Canadian society.

\section{REFERENCES}

1. Puzic S. Record number of refugees admitted to Canada in 2016, highest since 1980. CTV News [Internet]. 2017 Apr 24 [cited 2018 Nov 2];Canada:[about 3 p.]. Available from: https://www.ctvnews.ca/ canada/record-number-of-refugees-admitted-to-canada-in-2016highest-since-1980-1.3382444

2. Epp M. Refugees in Canada: a brief history. Ottawa: Canadian Historical Association; 2017. 33 p. (Immigration and ethnicity in Canada;35).

3. Belshaw JD. Canadian history: post-Confederation [Internet]. Victoria (BC): BCcampus; 2012. Chapter 5.11, Post war immigration; [cited 2018 Nov 2]; [about 9 p.] Available from: https://opentextbc.ca/ postconfederation/chapter/5-11-post-war-immigration/

4. Holtzer E, Moore-Dean A, Srikanthan A, et al. Reforming refugee healthcare in Canada: Exploring the use of policy tools. Health Policy. 2017;12(4):46-55. https://doi.org/10.12927/hcpol.2017.25099

5. Abdihalim H. Interim Federal Health Program for refugees: looking back and moving forward. Univ Ottawa J Med. 2012;6(2):33-5. https:// doi.org/10.18192/uojm.v6i2.1793

6. Barnes $\mathrm{S}$. The real cost of cutting the Interim Federal Health Program [Internet]. Toronto: Wellesley Institute; 2013 Oct [cited 2018 Nov 2]. Available from: https://www.wellesleyinstitute.com/wp-content/ uploads/2013/10/Actual-Health-Impacts-of-IFHP.pdf

7. Antonipillai V, Baumann A, Hunter A, et al. Impacts of the Interim Federal Health Program reforms: a stakeholder analysis of barriers to health care access and provision for refugees. Can J Public Heal. 2017;108(4):e435-41. https://doi.org/10.17269/cjph.108.5553

8. Turner JG. The Hospital Insurance and Diagnostic Services Act: its impact on hospital administration. CMAJ. 1958 May;78(10):768-70.

9. Mactavish J. Federal court of appeal between: Attorney General of Canada and Minister of Citizenship and Immigration and Canadian Doctors for Refugee Care, The Canadian Association of Refugee Lawyers, Daniel Garcia Rodriques, Hanif Ayubi and Justice for Children. 2014.

10. Yu S, Ouellet E, Warmington A. Refugee integration in Canada: a survey of empirical evidence and existing services. Refuge. 2007;24(2):17-34. https://doi.org/10.1007/s00425-007-0550-y

11. Eggertson L. Doctors promise protests along with court challenge to refugee health cuts. CMAJ. 2013;185(7):275-6. https://doi.org/10.1503/ cmaj.109-4430

12. Immigration, Refugees and Citizenshop Canada. Notice-changes to the Interim Federal Health Program [Internet]. Ottawa: Government of Canada; 2016 [cited 2018 Nov 2]. Available from: https://www. canada.ca/en/immigration-refugees-citizenship/news/notices/noticechanges-interim-federal-health-program.html

13. Oosterveld VL. The Canadian guidelines on gender-related persecution: an evaluation. Int J Refug Law. 1996;8(4):569-96. https:// doi.org/10.1093/ijrl/8.4.569

14. Redwood-Campbell L, Thind H, Howard M, et al. Understanding the health of refugee women in host countries: lessons from the Kosovar re-settlement in Canada. Prehosp Disaster Med. 2008 Aug;23(4)332-7. https://doi.org/10.1017/S1049023X00005951

15. Caulford P, D'Andrade J. Health care for Canada's medically uninsured immigrants and refugees Whose problem is it? Can Fam Physician. 2012;58(7):725-7.

16. Simich L, Wu F, Nerad S. Status and health security: An exploratory study of irregular immigrants in Toronto. Can J Public Heal. 2007;98(5):369-73. https://doi.org/10.1080/03637751.2011.646492

17. Magalhaes L, Carrasco C, Gastaldo D. Undocumented migrants in Canada: a scope literature review on health, access to services, and working conditions. J Immigr Minor Heal. 2010;12(1):132-51. https:// doi.org/10.1007/s10903-009-9280-5

18. Lowry M, Nyers P. "No one is illegal": The fight for refugee and migrant rights in Canada. Refuge. 2003;21(3):66-72.

19. Adams KM. Healthcare challenges from the developing world: postimmigration refugee medicine. Bmj. 2004;328(7455):1548-52. https:// doi.org/10.1136/bmj.328.7455.1548

20. Caulford P, Vali Y. Providing health care to medically uninsured immigrants and refugees. CMAJ. 2006;174(9):1253-4. https://doi. org/10.1503/cmaj.051206

21. Miedema B, Hamilton R, Easley J. Climbing the walls:structural barriers to accessing primary care for refugee newcomers in Canada. Can Fam Physician. 2008;54:335-6.

22. Ruiz-Casares M, Cleveland J, Oulhote Y, et al. Knowledge of healthcare coverage for refugee claimants: Results from a survey of health service providers in Montreal. PLoS One. 2016;11(1):e0146798. https://doi.org/10.1371/journal.pone.0146798

23. Gagnon AJ. Responsiveness of the Canadian health care system towards newcomers [Internet]. Discussion paper no. 40. Ottawa: Commission on the Future of Health Care in Canada; 2002 [cited 2018 Nov 2]. Available from: https://qspace.library.queensu.ca/bitstream/ handle/1974/6884/discussion_paper_40_e.pdf 